\title{
Study on Effect of Pretreatments and Microwave Drying On Banana Chips
}

\author{
Mr. Rushikesh Pandya * and Mr. Kailash Chandra Yadav \\ Sam Higginbottom Institute of Agriculture, Technology and Sciences, Vaugh School of Agricultural \\ Engineering and Technology, Department of Food Process Engineering, Allahabad-211007, U.P, India
}

\begin{abstract}
The study was conducted to evaluate the effect of pre-treatments (Control sample, Hot waterblanched sample and Citric acid blanched sample), power of microwave oven $(40 \mathrm{~W}, 60 \mathrm{~W}$ and $80 \mathrm{~W})$ and time on banana chips. To evaluate the effect of above mentioned parameters, chemical evaluation such as moisture content, fat content and ash content were carried out. Physical parameter such as blemish count was undertaken. Shrinkage in diameter and thickness of banana chips with respect to time of drying and power of microwave oven was also studied. Sensory analysis for colour, taste, texture, flavour, appearance and overall acceptability was carried out according to the 9 point hedonic scale.

The results showed that, the moisture loss from banana chips increased with increase in power of microwave oven and time of drying. More fat was lost with increase in power of microwave oven. Citric acid blanched sample showed more fat loss. There was no particular pattern for ash content found for any of the above mentioned treatments. The shrinkage of diameter and thickness of banana chips increased with increase in power of microwave oven and time of drying. Blemishes in banana chips increased with the increase in power of microwave oven. According to the overall sensory scores; banana chips prepared at $60 \mathrm{~W}$ of microwave power and by hot water blanched pre-treatment was the favorite among the panelists.
\end{abstract}

Key words: pre-treatments, microwave oven power.

\section{Introduction}

Banana (Musa paradisiaca L.) is the common name for herbaceous plants of the genusMusa and for the fruit they produce. Today; they are cultivated throughout the tropics. They are grown in at least 107 countries, primarily for their fruit, and to a lesser extent to make fiber and as ornamental plants. Many varieties of bananas are perennial (Wikipedia.com).Banana is the second largest produced fruit after citrus, contributing about $16 \%$ of the world's total fruit production. India leads in production of banana in the world with 28.2 metric tonnes of banana production per year. Cavendish' bananas are the main commercial cultivar. Banana is very perishable fruit. To avoid the losses and wastage of banana it can be dried or dehydrated to increase the shelf life of fruit. Drying brings about a substantial reduction in weight and volume; thereby minimizing packaging, storage and transportation cost and also enable storability of the product under ambient temperature especially in developing countries. Dried fruits are unique, tasty and nutritious. They are easy to handle and can be easily incorporated during food formulation and preparation. Dried fruit can be eaten as a snack or added to cereals, muffins or ice cream. Dehydrated banana fruit is used as a staple or important food in many parts of the world and also used in various food preparations.

\section{Sample Preparation}

\section{Materials And Methods}

Bananas were procured from local market of Allahabad; the selections of banana were unripe so as to get the best results. Samples were peeled, sliced into $2.5 \mathrm{~cm}$ diameter and $3 \mathrm{~mm}$ thickness.

\section{Pre-Treatments}

Control (Unblanched)

The banana chips were dehydrated without any treatment.

\section{Blanching}

The banana chips were blanched in hot water at $80^{\circ} \mathrm{C}$ for 1 minute to avoid loss of product firmness..

\section{Citric Acid Blanching}

This treatment consisted of blanching the banana chips in $5 \%$ citric acid solution at $80^{\circ} \mathrm{C}$ for 1 minute. 
Drying

In case of Household Microwave Oven, the banana chips were exposed to powers of 40W, $60 \mathrm{~W}$ and $80 \mathrm{~W}$, until the moisture content fell below $3 \%$ (w.b).

\section{Chemical Evaluation of Dried Banana Chips}

Moisture content: The moisture content of the banana sample was determined gravimetrically by drying thesample at $105^{\circ} \mathrm{C}$ until a constant weight was obtained. The result was expressed as percent moisture loss (wet basis).

Crude fat: Soxhlet extraction method was used.

Ash content: Banana sample $(2 \mathrm{~g})$ was weighed into a crucible and placed in a mottle furnace at $550^{\circ} \mathrm{C}$ for 3 $5 \mathrm{~h}$ until a whitish substance was obtained. Weight of ash was expressed as a percentage of the initial sample weight.

\section{Phyical estimation of dried banana chips: Chips Thickness and Diameter:}

The change in chip thickness and chip diameter of pre-treated banana chips on drying at different microwave powers and time were measured by screw gauge and vernier calliper respectively. This practice was repeated thrice to get a mean value and results which were recorded in $\mathrm{mm}$ as for thickness and in $\mathrm{cm}$ for diameter.

\section{Blemish Count:}

It is used to assess the appearance of the final product. Procedure:

Rehydrate $50 \mathrm{~g}$ representative sample of the dehydrated material. Visually count the number of surface blemishes. Multiply the number of blemishes by 2 and report the number of blemishes per $100 \mathrm{~g}$ of sample.

\section{Sensory Evaluation:}

Sensory analysis is a necessary part of product estimation as it gives an overview of the acceptance of product by customer. The sensory analysis was carried out with parameters undertaken as Colour, Taste, Flavour, Texture, Appearance and Overall acceptability. Sensory analysis was carried according to the 9 point hedonic scale.

\section{Statistical Analysis:}

The analysis were conducted by adopting Full factorial design, two level and three level, the data recorded during the course of research were statistically analyzed by the "Analysis of Variance". The significant effect of treatment was judged with the help of "F" (Variance ratio). Calculated F value was compared with the table value of $\mathrm{F}$ prob at $5 \%$ level of significance. If calculated value exceeded the table value, the effect was considered as significant. The significance of the study was tested at $5 \%$ level

\section{Effect of treatments on moisture content of banana chips.}

\section{Results And Discussions}

The mean scores for moisture content of banana chips dried with different treatments varied from 0.87 to 3.47. There was increase in moisture loss from banana chips with increase in microwave power and time of drying, this may be due to increase in conversion of water molecules into vapour with increase it power density and time of drying in microwave oven. Fig "1" shows the bar graph of moisture content of banana chips. The ANOVA showed significant effect of treatments on moisture content of banana chips at $5 \%$ level of significance. 


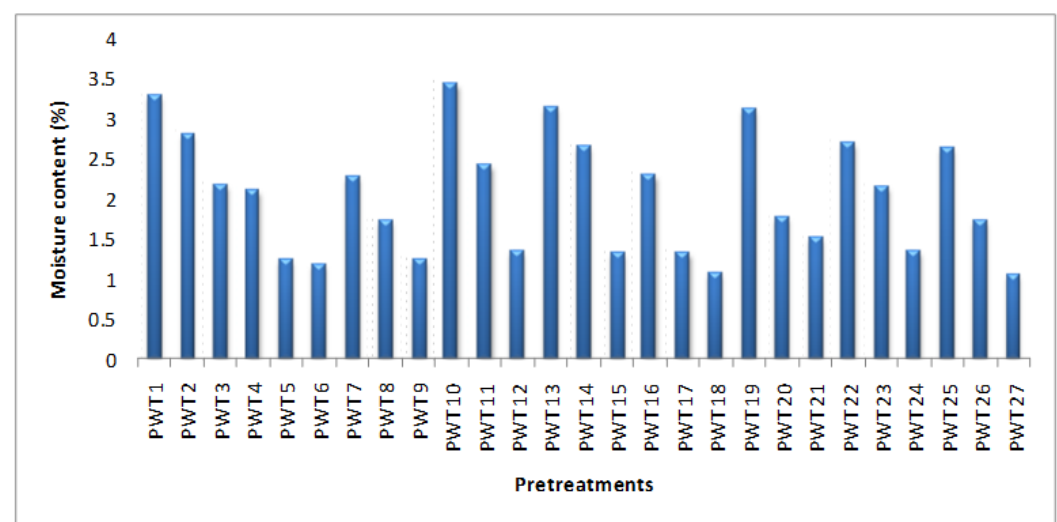

Fig 1: Moisture content of banana chipsEffect of microwave power and pre-treatments on Fat content of banana chips.

The fat content in dried banana chips varied from $1.42 \%$ to $2.19 \%$ with different treatments. The highest value of fat content (2.19\%) was for control sample dried at $40 \mathrm{~W}$ of microwave power and the lowest value $(1.42 \%)$ was for the citric acid blanched sample dried at microwave power of $80 \mathrm{~W}$. The fat loss increased from control sample to hot water blanched sample to citric acid blanched sample which showed most fat loss. Similarly, with increase in microwave power there was increase in fat loss from banana chips with samples dried at $80 \mathrm{~W}$ resulting in most fat loss Fig "2" shows the effect of microwave power and pre-treatment on fat loss of banana chips. The ANOVA showed significant effect of treatments on moisture content of banana chips at $5 \%$ level of significance.

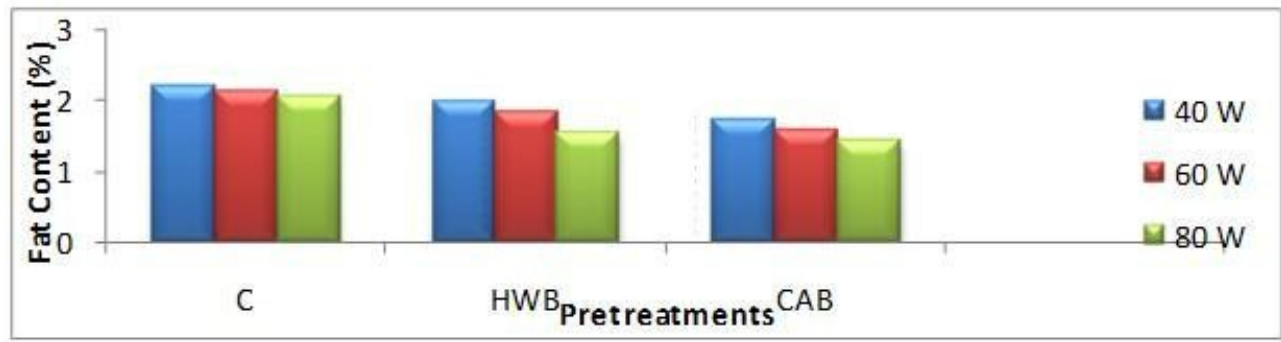

Fig 2: Effect of microwave power and pre-treatments on Fat content of banana chips

\section{Effect of Microwave power and pre-treatments on Ash content of banana chips}

The ash content of banana chips dried in microwave oven with different treatments varied from $0.81 \%$ to $0.87 \%$. There was no particular result obtained which would have verified the effective treatment resulting in changes in ash content of banana chips. The result obtained was similar to that obtained by Adeyemi O.S. Fig.3 shows the ash content of banana chips. The ANOVA showed significant effect of treatments on moisture content of banana chips at $5 \%$ level of significance.

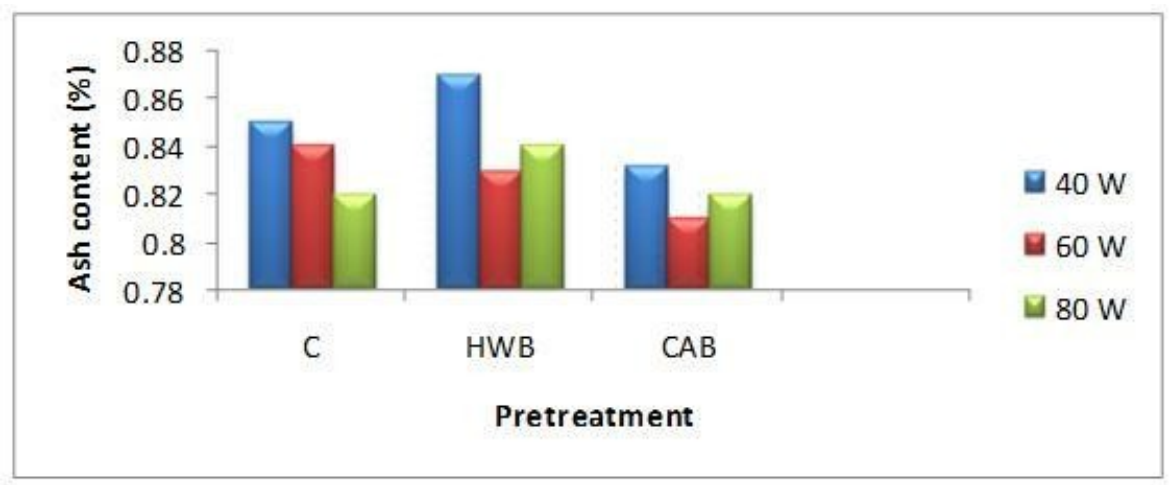

Fig 3 : Effect of Microwave power and pre-treatments on Ash content of banana chips

Shrinkage in pre-treated banana chips diameter dried at different microwave power and time.

The initial slice diameter was kept to be $2.5 \mathrm{~cm}$. At $40 \mathrm{~W}$, the shrinkage of diameter for control sample was $2.4 \mathrm{~cm}, 2.3 \mathrm{~cm}$ and $2.2 \mathrm{~cm}$ for 1 minute, 2 minutes and 3 minutes respectively. For HWB sample, the 
diameter shrinkage at $40 \mathrm{~W}$ was $2.3 \mathrm{~cm}, 2.3 \mathrm{~cm}$ and $2.2 \mathrm{~cm}$ for 1 minute, 2 minute and 3 minutes respectively. For CAB sample, at $40 \mathrm{~W}$ the diameter shrinkage was to $2.4 \mathrm{~cm}, 2.3 \mathrm{~cm}$ and $2.2 \mathrm{~cm}$ for 1 minute, 2 minutes and 3 minutes respectively. At $60 \mathrm{~W}$, the shrinkage of diameter for control sample was $2.4 \mathrm{~cm}, 2.2 \mathrm{~cm}$ and $1.9 \mathrm{~cm}$ for 1 minute, 2 minutes and 3 minutes respectively. For HWB sample, the diameter shrinkage at $60 \mathrm{~W}$ was $2.4 \mathrm{~cm}$, $2.2 \mathrm{~cm}$ and $2.0 \mathrm{~cm}$ for 1 minute, 2 minute and 3 minutes respectively. For CAB sample, at $60 \mathrm{~W}$ the diameter shrinkage was to $2.4 \mathrm{~cm}, 2.1 \mathrm{~cm}$ and $2.1 \mathrm{~cm}$ for 1 minute, 2 minutes and 3 minutes respectively. At $80 \mathrm{~W}$, the shrinkage of diameter for control sample was $2.3 \mathrm{~cm}, 2.1 \mathrm{~cm}$ and $1.8 \mathrm{~cm}$ for 1 minute, 2 minutes and 3 minutes respectively. For HWB sample, the diameter shrinkage at $80 \mathrm{~W}$ was $2.2 \mathrm{~cm}, 1.9 \mathrm{~cm}$ and $1.8 \mathrm{~cm}$ for 1 minute, 2 minute and 3 minutes respectively. For CAB sample, at $80 \mathrm{~W}$ the diameter shrinkage was to $2.0 \mathrm{~cm}, 1.9 \mathrm{~cm}$ and $1.8 \mathrm{~cm}$ for 1 minute, 2 minutes and 3 minutes respectively. The results indicated that there was increase in shrinkage of diameter with increase in microwave power and time of drying. The ANOVA showed significant effect of treatments on moisture content of banana chips at $5 \%$ level of significance.

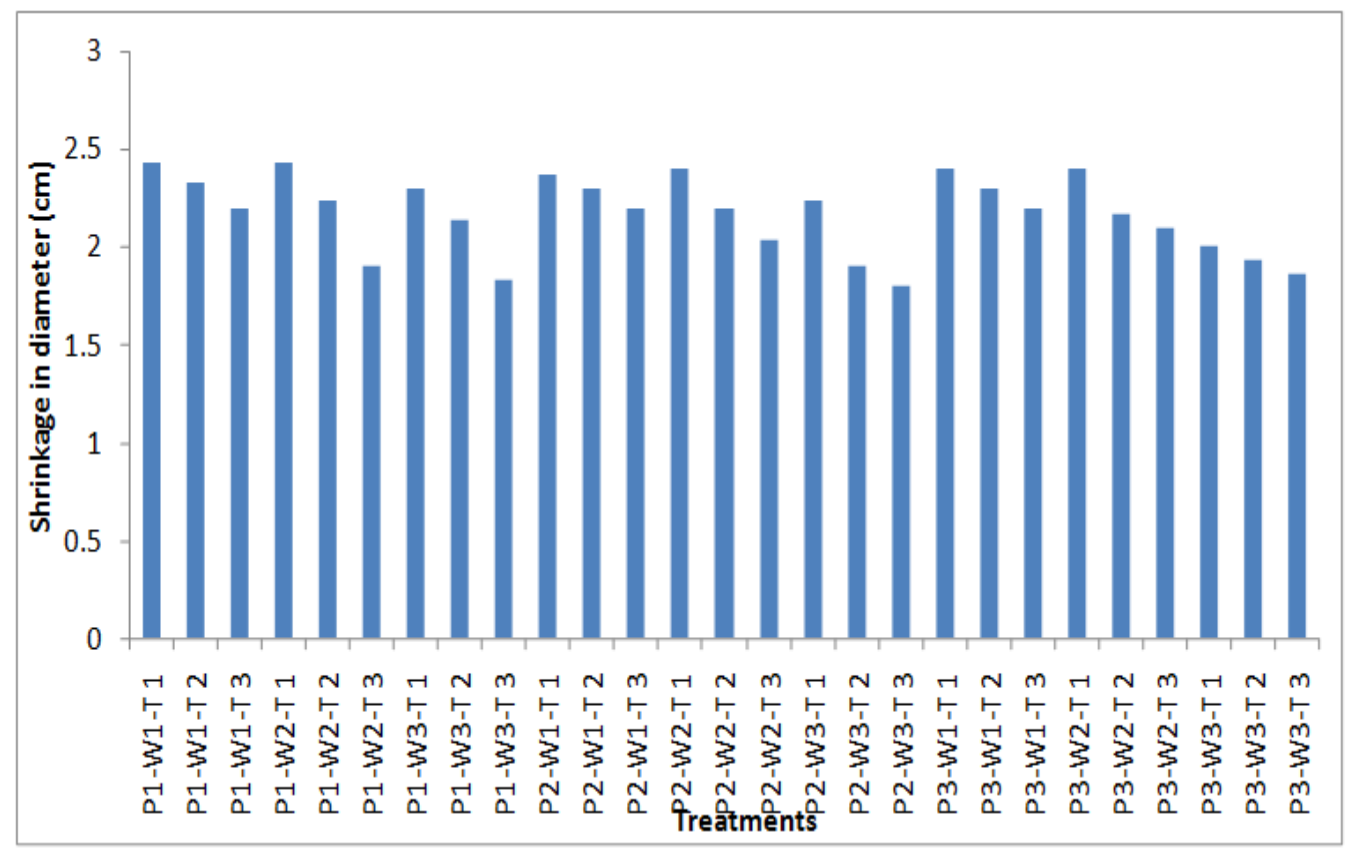

Fig 4: Shrinkage in pre-treated banana chips diameter dried at different microwave power and time.

The initial slice thickness was kept to be $3.0 \mathrm{~mm}$. At $40 \mathrm{~W}$, the shrinkage of thickness for control sample was $2.8 \mathrm{~mm}, 2.7 \mathrm{~mm}$ and $2.6 \mathrm{~mm}$ for 1 minute, 2 minutes and 3 minutes respectively. For HWB sample, the thickness shrinkage at $40 \mathrm{~W}$ was $3 \mathrm{~mm}, 2.7 \mathrm{~mm}$ and $2.5 \mathrm{~mm}$ for 1 minute, 2 minute and 3 minutes respectively. For CAB sample, at $40 \mathrm{~W}$ the thickness shrinkage was to $2.9 \mathrm{~mm}, 2.8 \mathrm{~mm}$ and $2.6 \mathrm{~mm}$ for 1 minute, 2 minutes and 3 minutes respectively. At $60 \mathrm{~W}$, the shrinkage of thickness for control sample was 2.9 $\mathrm{mm}, 2.7 \mathrm{~mm}$ and $2.5 \mathrm{~mm}$ for 1 minute, 2 minutes and 3 minutes respectively. For HWB sample, the thickness shrinkage at $60 \mathrm{~W}$ was $2.8 \mathrm{~mm}, 2.7 \mathrm{~mm}$ and $2.5 \mathrm{~mm}$ for 1 minute, 2 minute and 3 minutes respectively. For CAB sample, at $60 \mathrm{~W}$ the thickness shrinkage was to $2.9 \mathrm{~mm}, 2.7 \mathrm{~mm}$ and $2.5 \mathrm{~mm}$ for 1 minute, 2 minutes and 3 minutes respectively. At $80 \mathrm{~W}$, the shrinkage of thickness for control sample was $2.8 \mathrm{~mm}, 2.6 \mathrm{~mm}$ and $2.3 \mathrm{~mm}$ for 1 minute, 2 minutes and 3 minutes respectively. For HWB sample, the thickness shrinkage at $80 \mathrm{~W}$ was 2.6 $\mathrm{mm}, 2.4 \mathrm{~mm}$ and $2.1 \mathrm{~mm}$ for 1 minute, 2 minute and 3 minutes respectively. For CAB sample, at $80 \mathrm{~W}$ the thickness shrinkage was to $2.8 \mathrm{~mm}, 2.3 \mathrm{~mm}$ and $2.0 \mathrm{~mm}$ for 1 minute, 2 minutes and 3 minutes respectively. The results indicated that there was increase in shrinkage of diameter with increase in microwave power and time of drying. The ANOVA showed significant effect of treatments on moisture content of banana chips at 5\% level of significance. 


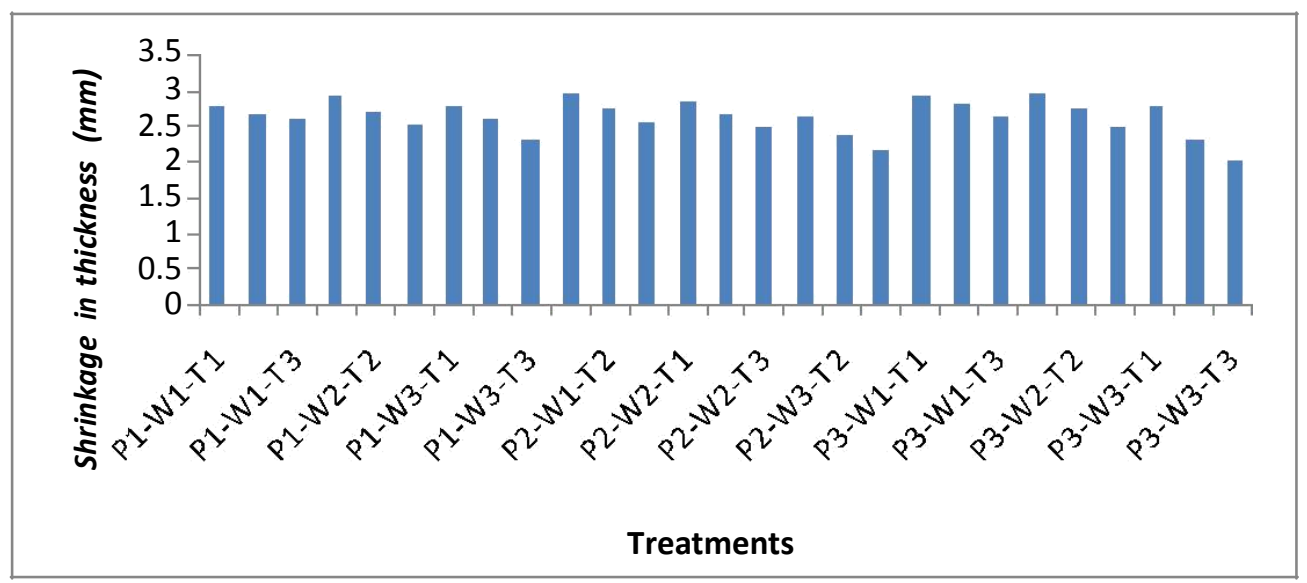

Fig 5: Shrinkage in pre-treated banana chips thickness dried at different microwave power and time.

\section{Blemish Count:}

Table 4.10 shows the mean score of blemish counts on banana chips. The results indicated that there was increase in blemishes in banana chips with increase in power of microwave oven. With respect to pretreatments, there was no significant variation in blemishes on banana chips. Fig 5 shows the blemish count on the banana samples

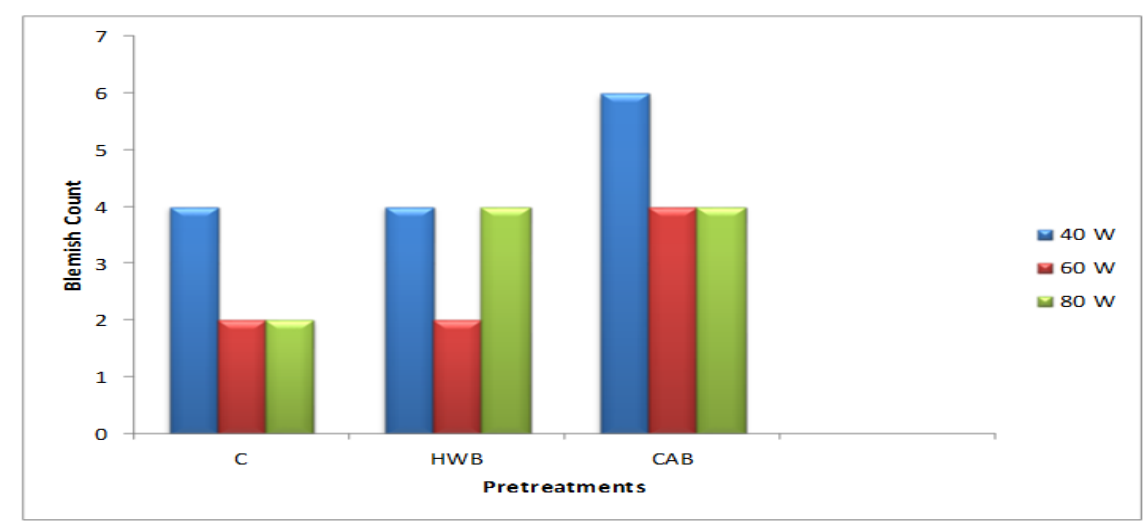

Fig 6: Effect of microwave power and pre- treatments on Blemish count in banana chips

\section{Sensory Evaluation}

According to the overall sensory scores, hot water blanched sample dried at $60 \mathrm{~W}$ of microwave power was the favourite for colour, taste, texture, flavor and overall acceptability.

For Appearance, banana chips prepared at $60 \mathrm{~W}$ with control (unblanched) pre- treatment was the favourite among the panelists. Even though the sensory scores for all the banana chips sample were ideal, the sample prepared at $60 \mathrm{~W}$ by hot water blanched pre-treatment was more optimum than the others in preparation of banana chips using microwave drying.

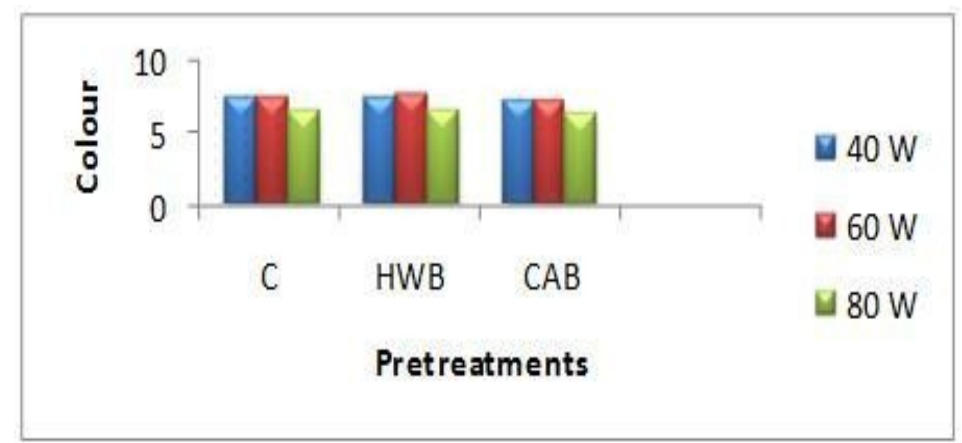

Fig 7: Effect of pre-treatment and microwave power on sensory score of colour of banana chips. 


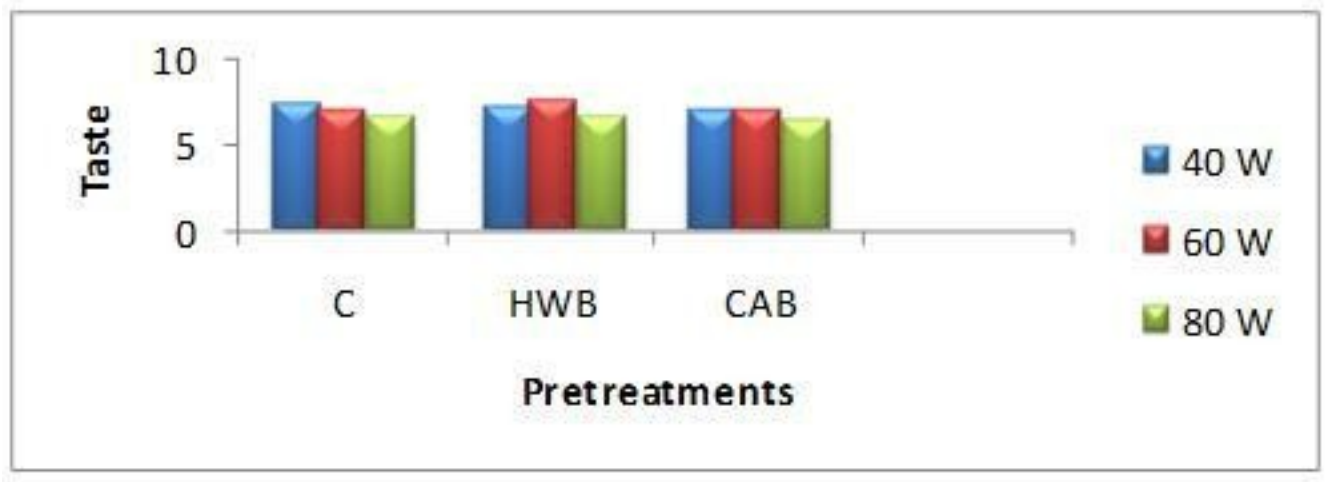

Fig 8: Effect of pre-treatments and microwave power on sensory score of taste of banana chips.

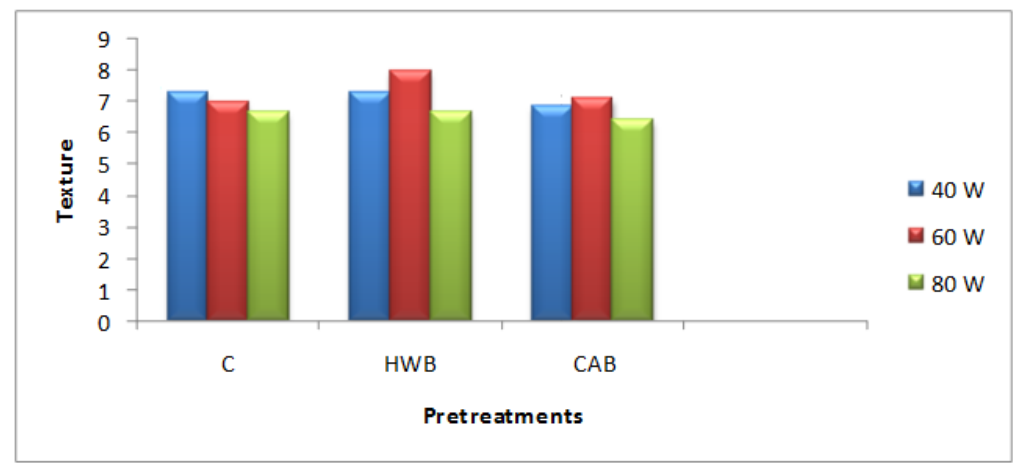

Fig 9: Effects of pre-treatments and microwave power on sensory score of texture of banana chips

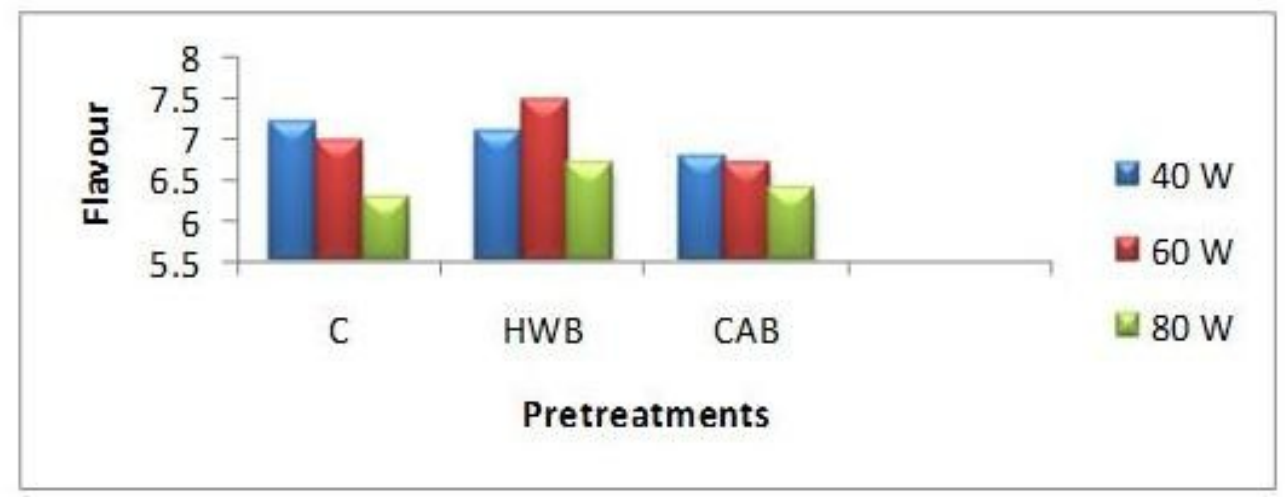

Fig 10: Effect of pre-treatments and microwave power on sensory score of flavour of banana chips

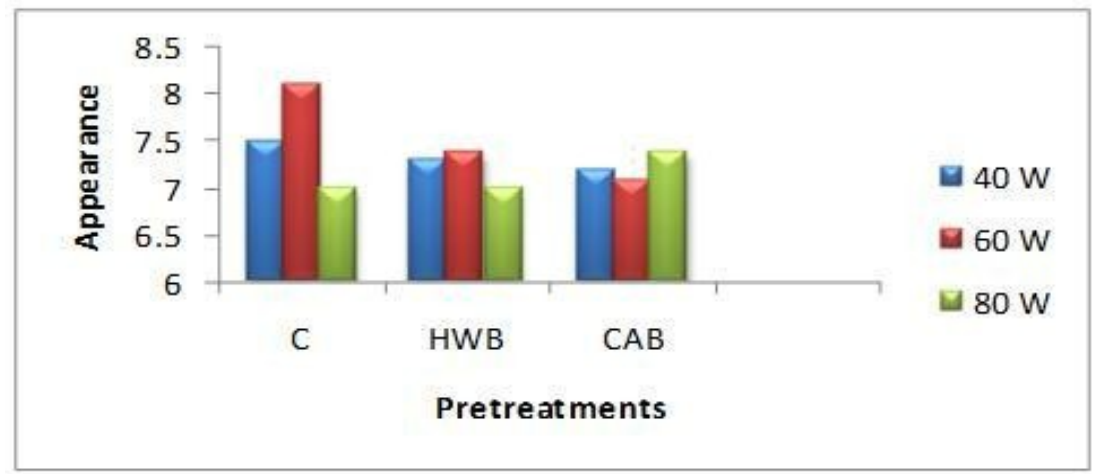

Fig 11: Effect of pre-treatments and microwave power on sensory score of appearance of banana chips 


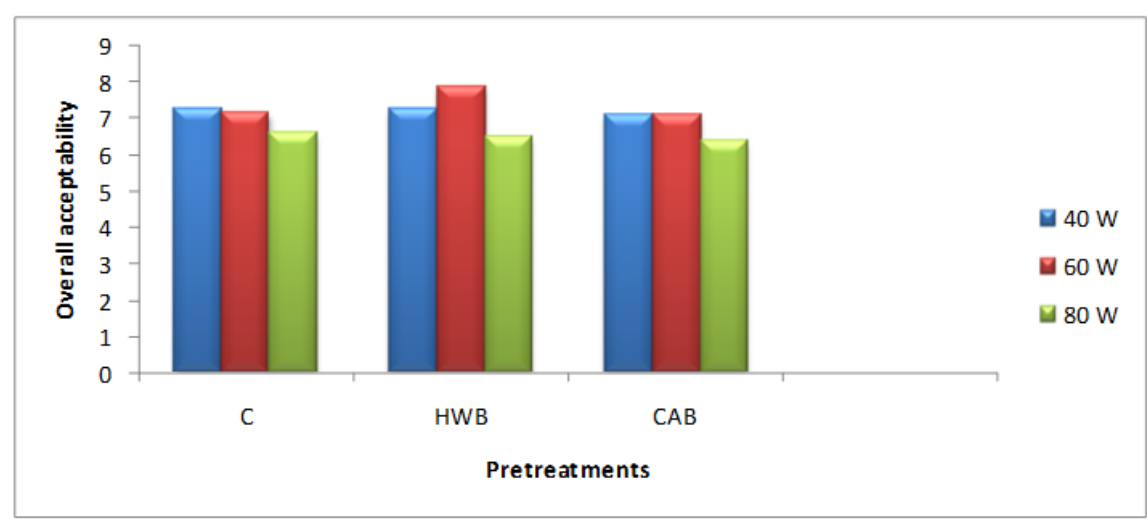

Fig 12: Effect of pre-treatments and microwave power on sensory score of overall acceptability Of banana chips

\section{Conclusion}

From the study it was concluded that, the moisture content is influenced by the power of microwave oven and the time chips took for drying. The fat content decreased with increase in microwave power. Ash content was not influenced by any of the treatments during microwave oven drying. Shrinkage increased with increase in microwave power and time of drying. The hot water blanched sample dried at $60 \mathrm{~W}$ microwave powers was the most accepted sample of banana chips with response to sensory scores.

\section{References}

[1]. Abano. E.E. (2010) Assessment of drying characteristics and physico-organoleptic properties of dried pineapple chips under different pre-treatments, Asian journal of Agricultural research 4 (3): 151-161

[2]. Abano E. E. and Sam-Amoah L. K. (2011) Effects of different pre-treatments on drying characteristics of banana slices, ARPN Journal of Engineering and Applied Sciences, Vol. 6, No. 3, March 2011

[3]. Adeyemi O. S. and Oladiji A. T ( 2009) Compositional changes in banana (Musa ssp.) fruits during ripening, African Journal of Biotechnology Vol. 8 (5), pp. 858-859, 6 March, 2009

[4]. Adom K.K., Dzogbefia V. P. and Ellis W. O. (1999) Combined Effect of Drying Time and Slice Thickness on the Solar Drying of Okra Journal of the Science of Food and Agriculture Volume 73, Issue 3, pages 315-320, March 1997

[5]. Agunbiade S.O., Olanlokun J.O. and Olaofe O.A. (2006) Quality of Chips Produced from Rehydrated Dehydrated Plantain and Banana Department of Biochemistry, Faculty of Science, University of Ado-Ekiti, Nigeria Pakistan Journal of Nutrition 5 (5):471473, 2006 ISSN 1680-5194 C Asian Network for Scientific Information, 2006471

[6]. Akoy El-Amin Omda Mohamed, Dieter Von Horsten and Wolfgang Luecke (2008) Drying Kinetics and Colour Change of Mango Slices as Affected by Drying Temperature and Time, Written for presentation at the 2008 Tropentag International Conference on

[7]. Brooks M.S., Abou El-Hana N.H. and Ghaly A.E. (2008) Effects of Tomato Geometries and Air Temperature on the Drying Behavior of Plum Tomato, American Journal of Applied Sciences 5 (10): 1369-1375, 2008 ISSN 1546-9239 @ 2008 Science Publications

[8]. Drying of Foods Practical Action Technical Brief Small-scale Drying Technologies Practical Action Technical Brief Adding Value to Bananas Food Chain No 21, July 1997, ITDG, Traditional Foods: Processing for Profit by P. Fellows, IT Publications, 1997

[9]. Gambella F, Piga, Agabbio. A. M, Vacca.V and Dhallewin G. (2000) Effect of different pre-treatments on drying of green table olives (Ascolana tenera var.), Grasas y Aceites, Vol 51, fasc 3. (2000) 173-176.

[10]. Gawade M.H and Waskar D.P. (2005) Effect of different varieties and pre-treatments on yield and of dried fig fruits, IndianJ. Agric. Res., $39(2): 138-141,2005$ 